Gut, 1982, 23, 770-773

\title{
Six years' experience of oesophageal transection for oesophageal varices, using a circular stapling gun
}

\author{
G W JOHNSTON \\ From the Royal Victoria Hospital, Belfast, Northern Ireland
}

SUMMARY Eighty patients with bleeding oesophageal varices, who were considered to be unfit for shunt surgery, were treated by oesophageal transection and subdiaphragmatic devascularisation. The overall hospital mortality was $14 \%$ and, after an average follow-up of nearly three years, $69 \%$ are still alive. Late recurrent bleeding occurred in 14 patients but varices were shown to be responsible in only four. Postoperative portal systemic encephalopathy has not been a problem.

There is no doubt that some form of portal systemic shunt provides the most effective means of preventing recurrent haemorrhage from oesophageal varices. The cost, however, is often high, because of gradual deterioration of liver function, and increased incidence of portal systemic encephalopathy. By careful selection of patients and probably by use of selective shunts, the incidence of disabling post-shunt encephalopathy can be reduced to more acceptable evels. Certainly, selectivity improves the morbidity and mortality figures for shunt surgery, but leaves a very large pool of 'shunt rejects'. Since 1958, the Royal Victoria Hospital, Belfast, has used injection sclerotherapy for these patients considered to be unfit for shunt, and we still continue to use this method. ${ }^{1}$ In January 1976 , we began evaluating a method of transabdominal oesophageal transection using a circular stapling gun for these patients unsuitable for shunt, ${ }^{2}$ and now report the results for the first six years.

\section{Methods}

\section{TECHNIQUE}

Since an earlier description of the method ${ }^{2}$ using the Russian SPTU gun, there have been some further developments. A number of circular stapling guns are now available, giving the surgeon a wider choice of instrument. We also feel that the transection should be carried out right at the oesophagogastric junction, or just immediately above, and not at $1.5-2.5 \mathrm{~cm}$ above the cardia as originally suggested. ${ }^{3}$ We are now meticulous in the devascularisation of

Received for publication 19 January 1982 the lower oesophagus. Not only is the left gastric vein routinely ligated at the upper border of the pancreas, but, in addition, the perioesophageal collaterals running with the vagal nerves are ligated and divided, and any branches from these vessels to the lowest $5 \mathrm{~cm}$ of the oesophagus are also divided. Splenectomy is added only if hypersplenism is demonstrated by a platelet count persistently below the $50000 / \mu l$ level.

\section{PATIENTS}

Since January 1976, we have performed 80 transabdominal oesophageal transections for bleeding oesophageal varices using a circular stapling gun. In 63 patients, the Russian SPTU gun was used; the American EEA stapler was used in 17. Of the 80 patients, 70 had cirrhosis and 10 had extrahepatic block (Table). All the cirrhotic patients were unsuitable for shunt surgery because of acute bleeding, poor liver function, or old age (17 were over 70 years old). The causes of intrahepatic obstruction are listed (Table) and it will be noted that $41 \%$ of the patients had alcoholic cirrhosis. In the 10 patients with extrahepatic block, transection was considered to be the operation of choice in the absence of veins suitable for shunting. The sex, age, and Child's classification of the patients are listed (Table).

\section{Results}

\section{COINCIDENTAL SPLENECTOMY}

In addition to oesophageal transection, 23 patients had splenectomy, and another patient had splenic artery ligation because of hypersplenism. Perhaps 
Table Details of patients

\begin{tabular}{|c|c|c|c|c|c|c|c|c|c|}
\hline \multirow[b]{2}{*}{ Aetiology } & & \multirow[b]{2}{*}{ Patients } & \multicolumn{2}{|c|}{ Sex } & \multirow{2}{*}{$\begin{array}{l}\text { Age } \\
(y r)\end{array}$} & \multirow{2}{*}{$\begin{array}{l}\text { Child's } \\
\text { class }\end{array}$} & \multicolumn{2}{|l|}{ Mortality } & \multirow[b]{2}{*}{ Rebleeding } \\
\hline & & & $M$ & $F$ & & & Operative & Late & \\
\hline Extrahepatic & & 10 & 7 & 3 & $38(14-58)$ & $10 \mathrm{~A}$ & 0 & 0 & 3 \\
\hline \multicolumn{10}{|l|}{ Intrahepatic } \\
\hline Alcoholic & 29 & & & & & & & & \\
\hline $\begin{array}{l}\text { Cryptogenic } \\
\text { Primary biliary }\end{array}$ & $\begin{array}{r}24 \\
6\end{array}$ & & & & & $23 \mathrm{~A}$ & 4 & 3 & 4 \\
\hline $\begin{array}{l}\text { Chronic active hepatitis } \\
\text { Fibrocystic disease }\end{array}$ & $\begin{array}{l}8 \\
1\end{array}$ & 70 & 37 & 33 & $56(15-81)$ & $16 \mathrm{~B}$ & 1 & 2 & 2 \\
\hline $\begin{array}{l}\text { Haemachromotosis } \\
\text { Lupoid hepatitis }\end{array}$ & $\begin{array}{l}1 \\
1\end{array}$ & & & & & $31 \mathrm{C}$ & 6 & 9 & 5 \\
\hline Total & & 80 & 44 & 36 & $54(14-81)$ & $33 \mathrm{~A}, 16 \mathrm{~B}, 31 \mathrm{C}$ & 11 & 14 & 14 \\
\hline
\end{tabular}

surprisingly, splenectomy did not appear to increase the operative risk. Three of these 24 patients died two to three weeks after operation from hepatic failure; two were Child's grade $C$ and one Child's grade $B$. It is worth noting that two of the post-splenectomy patients subsequently developed mesenteric thrombosis requiring small bowel resection some months after the initial surgery. Both these patients had extrahepatic block and both survived the second operative procedure. There has been no problem with post-splenectomy sepsis in this group of patients, and, indeed, there has been only one late death at 25 months from haemorrhagic gastritis in an alcoholic who continued drinking. No patient in this group has had recurrent bleeding from varices.

\section{COMPLICATIONS OF OPERATION}

\section{Dysphagia}

Many patients developed some minor dysphagia for a few weeks after starting on solid food. In the majority, this settled spontaneously, but $11(16 \%)$ of the 69 patients who survived operation required oesophageal dilatation with Eder-Peustow dilators. Five patients were dilated once; three required two dilatations; one required four; one five and one six before getting relief. Dysphagia seems to have been more of a problem in the early part of the series, with four of the first 12 patients needing dilatation. Initially, we performed the transection about 1.5$2.5 \mathrm{~cm}$ above the cardia, as suggested by Van Kemmel. ${ }^{3}$ Subsequently, we changed the site of transection to immediately above the oesophagogastric junction. Perhaps the earlier transections left a functioning but isolated cardiac spincter which failed to act in co-ordination with deglutition. Unfortunately, our attempts at postoperative oesophageal pressure studies were unhelpful on this point. Obviously any transection interferes with the delicate anti-reflux mechanism and it is not surprising that some patients also complain of heartburn after operation. Because of the increased risk of reflux, we advise all patients to take one of the alginic acid preparations after meals and last thing at night before retiring.

\section{Leakage}

No patient developed a leak from the oesophageal transection suture line. One patient, however, did have a fatal mediastinal leak from the oesophagus about $2 \mathrm{~cm}$ above the anastomosis. This had resulted from an unrecognised perforation during intraoperative dilatation from below of a pre-existing stricture in order to allow passage of the head of the gun; the actual anastomosis remained intact. One other patient developed a leak from his gastrotomy wound resulting in a subphrenic abscess: the fistula closed spontaneously on drainage of the abscess.

\section{Portal systemic encephalopathy}

Postoperative portal systemic encephalopathy has not been a problem; only three patients have needed hospital admission with this complication. Two patients had transient attacks within the first six months of operation, and none in the subsequent period of follow-up. The other patient who had had frequent episodes of encephalopathy before surgery continued to do so after operation. The attacks were precipitated by repeated episodes of bleeding from gross erosive gastritis and the patient eventually died from this cause. Comparisons of hepatic blood flow using radioactive technetium colloid before and after transection have demonstrated that the portal blood flow is not reduced. Indeed, where a large spleen has been removed at the time of transection, the hepatic arterial inflow may be enhanced, presumably because of elimination of the 'splenic steal' from the coeliac axis via the splenic artery. 
Thus, unlike the situation after shunt surgery, the total liver profusion is not reduced, and, hence, one would not expect any increased incidence of encephalopathy as a result of operation.

\section{Recurrent haemorrhage}

Of the 69 patients who survived to leave hospital, 14 have had further bleeding episodes and five have died. Endoscopy was carried out in 13 of the 14 patients. The other patient died without endoscopy outside hospital during a heavy drinking bout. Of the 13 patients who were endoscoped, varices were the source of bleeding in four, gastritis in four, Mallory-Weiss ulceration in one; prepyloric ulceration in one, and stomal ulceration in one; in two patients with melaena only, no source of bleeding was demonstrated. In addition to the one patient who died outside hospital without the source of bleeding being diagnosed, three other deaths occurred in the gastritis group, and one in the varices group. In the four incidences of recurrent varices, usually only one column of varices was present and this was much smaller than preoperatively. All four patients received injection sclerotherapy and one has proceeded to elective splenorenal shunt.

\section{Mortality}

The overall hospital mortality for the whole series was $14 \%$, six of the 11 deaths occurring in Child's grade $\mathrm{C}$ patients (Table). Most of the hospital deaths were due to liver failure, often progressing to multiple organ failure. In two patients, however, unsuspected low grade intraperitoneal sepsis was the precipitating factor. Of the 19 patients submitted to emergency transection, six died, giving a $32 \%$ mortality for the emergency operation. This contrasts sharply with the $8 \%$ mortality in the other 61 patients where the operation was carried out at least 48 hours, and often many weeks, after the last haemorrhage.

Of the 69 patients who survived to leave hospital, 14 have died after an average period of 16 months. Nine of these late deaths occurred in Child's grade C patients. Five deaths occurred as a result of bleeding and are listed above. The other late deaths were due to liver failure in four patients, primary hepatoma, carcinoma of the larynx, carcinoma of the lung, bronchopneumonia, and cerebral vascular accident respectively in the others. Thus, 55 of the original 80 patients $(69 \%)$ are still alive after an average follow-up of almost three years.

\section{Discussion}

Over the years, there has been a tendency for centres concerned with the management of bleeding varices to adhere to one method of treatment enjoying popularity at the time. Ideally, we should try to match one of the available treatments to each individual patient, as was first suggested by Child in $1964 .^{4}$ The initial emergency management is well established and includes the use of fresh blood, continuous intravenous infusion of pitressin, oesophageal tamponade, and measures to combat coma. Where bleeding is not controlled by a conservative regime, or where bleeding recurs, we have favoured the use of emergency injection sclerotherapy via the rigid oesophagoscope and we still advocate this approach. Although we did use emergency transection for 19 patients with acute bleeding, the $32 \%$ mortality was unacceptable and we have reverted to injection sclerotherapy for emergency control of bleeding.

Where bleeding stops with conservative measures and does not recur on discontinuance of pitressin or tamponade, emergency surgery should be avoided and the patient tided over for some weeks, when a definitive operation can be carried out with greater safety. For a percentage of younger patients with good liver function, this will mean an elective shunt, preferably a selective one, thus giving the most effective therapy against recurrent bleeding with an acceptable rate of encephalopathy. For those patients considered to be unsuitable for shunt, we use either injection sclerotherapy or oesophageal transection within a few weeks or as soon as the patient is considered fit. Where there is resistant ascites or poor liver function, sclerotherapy is preferred as laparotomy is best avoided. Thus, 61 'elective' transections in this series are somewhat selected in that, although the best patients were excluded and reserved for shunt surgery, some of the worst patients have also been excluded, and managed by injection sclerotherapy. The problem with sclerotherapy - whether it be by means of the rigid oesophagoscope, the flexible endoscope, or the percutaneous transhepatic route - is that vessel recanalisation and recurrent bleeding are almost inevitable unless a course of chronic injections is undertaken. ${ }^{5} 6$

Although varices often extend throughout the length of the oesophagus and sometimes into the stomach, bleeding is almost always localised to the 5 $\mathrm{cm}$ just above the cardia. Histological examination of the oesophageal rings removed at transection has demonstrated large dilated venous channels immediately below the epithelium and superficial to the muscular mucosa. In addition, there are dilated intraepithelial blebs, 'varices upon varices', often with only a few layers of cells separating the vessel lumen from that of the oesophagus. ${ }^{7}$ These thin- 
walled intraepithelial blebs, the 'cherry-red spots' seen at endoscopy, are obviously most susceptible to rupture when subjected to the sudden rises in portal pressure which occur during straining or coughing. The picture is akin to that of varicose veins of the lower limbs, where the high pressure 'blow-out' coupled with the hypoxia of chronic venous congestion causes thinning of the overlying epithelium.

The management of bleeding varices by a direct attack on this vulnerable area is attractive in that it avoids precipitating the problem of encephalopathy which occurs in over one-third of patients subjected to shunt surgery. Since Boerema ${ }^{8}$ and Crile $^{9}$ pioneered direct transoesophageal ligation of varices, their technique and various other oesophagogastric devascularisation procedures have been widely used. The use of the circular stapling gun for oesophageal transection was first reported by Van Kemmel ${ }^{3}$ in 1974. The advantage of this simple method is that it gives full thickness oesophageal transection via the abdominal approach and allows subdiaphragmatic devascularisation at the same time. Perhaps the ligation of the left gastric vein, the meticulous division of the perioesophageal collateral vessels, and splenectomy where indicated are just as important as the actual transection in preventing recurrence of the varices. Certainly, Hassab has reported excellent results for his decongestion operation without transection. ${ }^{10}$ Sugiura's extensive devascularisation operation includes transection, but it requires thoracotomy as well as laparotomy and is not well tolerated by many of the cirrhotic patients seen in Western society. ${ }^{11}$

Obviously, oesophageal transection and devascularisation operations cannot be as effective as shunting in preventing recurrent bleeding in the long-term. Unlike portal systemic shunts, however, transection does not divert any blood from the liver, and therefore does not increase the patient's risk of portal systemic encephalopathy. It is therefore most useful in those patients susceptible to post-shunt encephalopathy - namely, patients with varices due to bilharzial cirrhosis, other cirrhotics over 50 years of age, those with Child's grade C liver dysfunction, and those with a history of diabetes or previous encephalopathy. It is not suggested that gun transection should replace established methods of treatment, but it is felt that it is a useful addition to the procedures already in use. Longer follow-up is required before a full assessment of the risk of recurrent bleeding can be really meaningful, but the results of the first six years are encouraging.

\section{References}

1 Johnston GW, Rodgers HW. A review of 15 years' experience in the use of sclerotherapy in the control of acute haemorrhage from oesophageal varices. $\mathrm{Br} J$ Surg 1973; 60: 797-800.

2 Johnston GW. Treatment of bleeding varices by oesophageal transection with the SPTU gun. Ann $R$ Coll Surg Engl 1977; 59: 404-8.

3 Van Kemmel M. Resection-anastomose de l'oesophage sus-cardial pour rupture de varices oesophagiennes. Nouv Presse Med 1974; 5: 1123-4.

4 Child CG. The liver and portal hypertension. Philadelphia and London: Saunders, 1964: 50.

5 Clark AW, MacDougall BRD, Westaby D et al. Prospective controlled trial of injection sclerotherapy in patients with cirrhosis and recent variceal haemorrhage. Lancet 1980; 2: 654-60.

6 Terblanche J, Northover JMA, Bornman P et al. A prospective controlled trial of sclerotherapy in the long term management of patients after esophageal variceal bleeding. Surg Gynecol Obstet 1979; 148: 323-33.

7 Johnston GW. Bleeding oesophageal varices: the management of shunt rejects. Ann R Coll Surg Engl 1981; 63: 3-8.

8 Boerema I. Bleeding varices of the oesophagus in cirrhosis of the liver and Banti's disease. Arch Chir Neerl 1949; 1: 253-60.

9 Crile GS. Transoesophageal ligation of bleeding oesophageal varices: a preliminary report of 7 cases. Arch Surg 1950; 61: 654-60.

10 Hassab MA. Gastroesophageal decongestion and splenectomy in the treatment of oesophageal varices in bilharzial cirrhosis: further studies with a report on 355 operations. Surgery 1967; 61: 169-76.

11 Sugiura M, Futagawa S. A new technique for treating oesophageal varices. J Thorac Cardiovasc Surg 1973; 66: 677-85. 